\title{
Aromatic ring formation in opposed-flow diffusive 1,3-butadiene flames
}

\author{
Kai Moshammer ${ }^{1}$, Lars Seidel ${ }^{2}$, Yu Wang ${ }^{3,4}$, Hatem Selim ${ }^{3}$, S. Mani Sarathy ${ }^{3}$, Fabian \\ Mauss $^{2}$, Nils Hansen ${ }^{1 *}$ \\ ${ }^{1}$ Combustion Research Facility, Sandia National Laboratories, Livermore, CA 94551, USA \\ ${ }^{2}$ Thermodynamics and Thermal Process Engineering, Brandenburg University of Technology, \\ Siemens-Halske-Ring 8, D-03046 Cottbus, Germany \\ ${ }^{3}$ Clean Combustion Research Center, King Abdullah University of Science and Technology, \\ Thuwal 23955-6900, Saudi Arabia \\ ${ }^{4}$ School of Automotive Engineering, Wuhan University of Technology, Wuhan 430070, P.R. China \\ Corresponding author: Nils Hansen, email: nhansen@sandia.gov
}

\section{Colloquium:}

SOOT, NANOPARTICLES, PAH AND OTHER LARGE MOLECULES

\section{Word Count (Method 1):}

\begin{tabular}{|lc|}
\hline Abstract & 209 \\
\hline Main Text & 3928 \\
References & 647 \\
Figure 1 & 179 \\
Figure 2 & 383 \\
Figure 3 & 148 \\
Figure 4 & 274 \\
Figure 5 & 247 \\
Figure 6 & 390 \\
\hline Total (excl. abstract) & 6196 \\
\hline
\end{tabular}

Color figures in electronic version only. Supplemental Material is available. 


\title{
Aromatic ring formation in opposed-flow diffusive 1,3-butadiene flames
}

\author{
Kai Moshammer ${ }^{1}$, Lars Seidel ${ }^{2}$, Yu Wang ${ }^{3,4}$, Hatem Selim ${ }^{3}$, S. Mani Sarathy ${ }^{3}$, Fabian \\ Mauss $^{2}$, Nils Hansen ${ }^{1 *}$ \\ ${ }^{1}$ Combustion Research Facility, Sandia National Laboratories, Livermore, CA 94551, USA \\ ${ }^{2}$ Thermodynamics and Thermal Process Engineering, Brandenburg University of Technology, \\ Siemens-Halske-Ring 8, D-03046 Cottbus, Germany \\ ${ }^{3}$ Clean Combustion Research Center, King Abdullah University of Science and Technology, \\ Thuwal 23955-6900, Saudi Arabia \\ ${ }^{4}$ School of Automotive Engineering, Wuhan University of Technology, Wuhan 430070, P.R. China
}

\begin{abstract}
This paper is concerned with the formation of one- and two-ring aromatic species in near atmospheric-pressure opposed-flow diffusion flames of 1,3-butadiene $\left(1,3-\mathrm{C}_{4} \mathrm{H}_{6}\right)$. The chemical structures of two different $1,3-\mathrm{C}_{4} \mathrm{H}_{6} / \mathrm{Ar}-\mathrm{O}_{2} / \mathrm{Ar}$ flames were explored using flame-sampling molecular-beam mass spectrometry with both electron and single-photon ionization. We provide mole fraction profiles of 47 components as function of distance from the fuel outlet and compare them to chemically detailed modeling results. To this end, the hierarchically developed model described by Seidel et al. [Combust. Flame 162 (2015) 2045-2058] has been updated to accurately comprise the chemistry of 1,3-butadiene. Generally a very good agreement is observed between the experimental and modeling data, allowing for a meaningful reaction path analysis. With regard to the formation of aromatic species up to naphthalene, it was essential to improve the fulvene and the $C_{5}$ chemistry description in the mechanism. In particular, benzene is found to be formed mainly via fulvene through the reactions of the $\mathrm{C}_{4} \mathrm{H}_{5}$ isomers with $\mathrm{C}_{2} \mathrm{H}_{2}$. The $n-\mathrm{C}_{4} \mathrm{H}_{5}$ radical reacts with $\mathrm{CH}_{3}$ forming 1,3-pentadiene $\left(\mathrm{C}_{5} \mathrm{H}_{8}\right)$, which is
\end{abstract}


subsequently oxidized to form the naphthalene precursor cyclopentadienyl $\left(\mathrm{C}_{5} \mathrm{H}_{5}\right)$. Oxidation of naphthalene is predicted to be a contributor to the formation of phenylacetylene $\left(\mathrm{C}_{8} \mathrm{H}_{6}\right)$, indicating that consumption reactions can be of similar importance as molecular growth reactions.

Keywords: 1,3-butadiene, diffusion flame, mass spectrometry, modeling, PAH formation 


\section{Introduction}

1,3-Butadiene $\left(\mathrm{CH}_{2}=\mathrm{CH}-\mathrm{CH}=\mathrm{CH}_{2}, 1,3-\mathrm{C}_{4} \mathrm{H}_{6}\right)$ is a gaseous fuel with a complex combustion chemistry, which is not yet understood in detail. This molecule is studied for a variety of reasons. It is a common intermediate in hydrocarbon combustion and it is emitted as an unwanted, toxic byproduct from internal combustion engines. As a small di-ene, $1,3-\mathrm{C}_{4} \mathrm{H}_{6}$ represents this class of compounds in practical fuels. In addition, 1,3- $\mathrm{C}_{4} \mathrm{H}_{6}$ is a good source of $\mathrm{C}_{4} \mathrm{H}_{5}$ radicals that are involved in the formation of aromatic species [1]. It is therefore considered to be an important $\mathrm{C}_{4}$ fuel for the development of a hierarchical combustion chemistry model for small hydrocarbons.

With regard to aromatics formation in $1,3-\mathrm{C}_{4} \mathrm{H}_{6}$ flames, the importance of various pathways was discussed in the literature [2-8]. The formation of aromatic species has been described by Granata et al. [5], who modeled opposed-flow flame structures obtained by Olten and Senkan [4]. Specifically for benzene, the latest results indicate that addition of $i-\mathrm{C}_{4} \mathrm{H}_{5}$ $\left(\mathrm{CH}_{2}=\mathrm{CH}-\mathrm{C}=\mathrm{CH}_{2}\right)$ to $\mathrm{C}_{2} \mathrm{H}_{2}$ is of significance as well as contributions from reactions of propargyl $\left(\mathrm{C}_{3} \mathrm{H}_{3}\right)$ and allyl $\left(\mathrm{C}_{3} \mathrm{H}_{5}\right)$ radicals [8]. The authors provided a chemically detailed description of benzene formation in 1,3-butadiene flames including the fulvene chemistry, which requests a re-investigation of the formation pathways of larger aromatics.

To this end, we have determined the detailed chemical structures of two near atmospheric-pressure opposed-flow diffusion flames of $1,3-\mathrm{C}_{4} \mathrm{H}_{6}$ with flame-sampling mass spectrometry and compared the centerline mole fraction profiles of many species with results from combustion chemistry modeling. The model's predictive capabilities were also assessed against other opposed-flow diffusion and premixed 1,3-butadiene flame structures [4,8]. A 
reaction pathway analysis revealed interesting insights into, for example, the importance of the $\mathrm{C}_{5}$-chemistry, which results from addition reactions to the fuel radical, and the sensitive concurrence of molecular growth and consumption reactions in formation of aromatic species.

\section{Experimental details and data evaluation}

A non-premixed, opposed-flow burner system was coupled to a high-resolution time-of-flight molecular-beam mass spectrometer. Details of the experimental setup are described elsewhere [9-11], thus only a short description is given here.

The burner system is based on two opposing gas-outlets with each consisting of two concentric tubes with inner diameters of $14 \mathrm{~mm}$ and $20 \mathrm{~mm}$, respectively. In this setup the argon-diluted reactants flow through the inner tubes whereas the outer rings provide argon coflows that shield and stabilize the flame. The distance between the upper (oxygen+argon) and the bottom (fuel+argon) tubes is $12 \mathrm{~mm}$. The flame gases are sampled via a horizontally mounted quartz nozzle (details see Fig. S1) vertically along the center line of the flame and guided into a two-stage differentially pumped vacuum chamber of the mass spectrometer.

The instrument is a custom-built reflectron time-of-flight mass spectrometer, which provides a resolution of $\mathrm{m} / \Delta \mathrm{m} \sim 3500$, a sensitivity limit of $\sim 1 \mathrm{ppm}$, and a dynamic range of six orders of magnitudes. It is routinely used with photoionization by synchrotron-generated vacuum-ultraviolet (VUV) radiation and is additionally equipped with an electron gun enabling measurements using electron ionization (EI).

Two different 1,3-butadiene/Ar- $\mathrm{O}_{2} / \mathrm{Ar}$ flames were investigated, with their mass fractions being 7.7\% 1,3- $\mathrm{C}_{4} \mathrm{H}_{6} / 92.3 \% \mathrm{Ar}-16.7 \% \mathrm{O}_{2} / 83.3 \% \mathrm{Ar}$ (Flame A) and 10\% 1,3- $\mathrm{C}_{4} \mathrm{H}_{6} / 90 \% \mathrm{Ar}-$ 
$16.7 \% \mathrm{O}_{2} / 83.3 \% \operatorname{Ar}$ (Flame B). The flame conditions were chosen to be mainly particle free (Flame A; allowing for an investigation of the formation of the first aromatic ring) and to have a slight soot layer (Flame B; enabling the detection of larger aromatic species). The gas velocities through the fuel and oxidizer ports were kept constant for both flames at $22.20 \mathrm{~cm} / \mathrm{s}$ and $22.12 \mathrm{~cm} / \mathrm{s}$, respectively. The flames were kept at a near-atmospheric pressure of 700 Torr. Species profiles were recorded as a function of mass-to-charge $(\mathrm{m} / \mathrm{z})$ ratio and as distance from the fuel outlet.

Mole fraction profiles of 38 species were derived for Flame A and Flame B using the El technique, which precludes isomer-resolved speciation. To provide partially isomer-specific information, we performed complementary experiments for Flame A using photoionization by synchrotron-generated VUV radiation at the Chemical Dynamics Beamline of the Advance Light Source [12].

Much of the data evaluation procedures applied here for the opposed-flow flames corresponds to the approach for premixed flames that have been described in detail for El and PI experiments elsewhere $[13,14]$ and are not repeated here. The key aspects of the procedures are summarized in the Supplemental Material. As discussed in Refs. [13-15], the accuracy of the absolute mole fractions depends on many factors and uncertainties of $\pm 20 \%$ for major species as well as a factor of 2-4 for intermediate species are expected. A direct calibration for methane, acetylene, ethylene, propyne, propene, propane, 1-butene, butane, benzene, and toluene was performed in the El experiment reducing the experimental uncertainties for these species to $\pm 30 \%$. Experimental mole fraction profiles derived from El and PI measurements are in addition consistent within the given error limits. 
Temperature profiles were obtained from the temperature dependence of the sampling rate. This method, which automatically corrects for the flame disturbance by the nozzle, has been shown as an accurate approach for flame-sampling experiments $[14,16]$. Estimating the temperature close to the fuel outlet to be $330 \mathrm{~K}$, we obtained a reasonable temperature profile that is shown below in Fig. 1 for Flame A (and Fig. S2 of the Supplemental Material) as dashed grey line. The thin lines provide an upper and lower limit for the temperature profile when estimating a gas temperature at the outlet of $350 \mathrm{~K}$ or $298 \mathrm{~K}$, respectively. The profile estimating $330 \mathrm{~K}$ on the fuel side was used as reference for the simulations. The temperature profile for Flame B is shown in Fig. S3 of the Supplemental Material. Note that the provided temperature profiles are the probe-disturbed ones and thus already include the cooling effect of the nozzle to the flame. Temperature profiles neglecting the probe influence (e.g. determined with thermocouples), as mostly discussed in the literature, have therefore higher peak temperatures. As a consequence, the provided mole fraction profiles should not be considered to be representative of the unperturbed temperature profile.

\section{Kinetic mechanism}

A chemical kinetic model, that has been under continuous development for several years, was updated to include the oxidation of 1,3-butadiene in more detail than before. The model is based on a series of former development steps which include a broadly validated reaction mechanism for the $C_{1}-C_{4}$ chemistry $[14,17,18]$, 1-hexene [19], and $n$-heptane [16], with the latter being the base model for the improvements described here. The hierarchically constructed mechanism is validated against speciation data from premixed low-pressure 
flames, laminar flame speeds at different pressures, and ignition delay time measurements (for examples see Supplemental Material of Ref. [16]). In this stage of the development, the model's capabilities were also tested against speciation data from diffusion flames, thus adding another level of complexity.

Detailed information about the kinetic and thermodynamic properties of most reactions and species in the present model are provided extensively in previous works [16]. In this work, only the reactions of acetylene with radicals in the $C_{1}$ to $C_{3}$ core model were revised using updated rates from Refs. $[20,21]$. All other modifications are related to larger species and are documented in detail in the header of the reaction mechanism. Thermodynamic data for some key species were updated based on the Goos/Burcat/Ruscic data base [22]. The updated mechanism consists of 346 species and 3710 elementary reactions. It is available together with the transport and thermodynamic data in the Supplemental Material. Modifications leading to major improvements are discussed in the following paragraphs. It is important to note that the updated mechanism kept the quality of the predictions for previously used validation targets (see Figs. S4-S7).

Model calculations were performed with the current version of the LOGEsoft package [23]. The experimentally derived temperature profiles were not imposed for model calculations, because such an approach led to an over-compensation of the probe-induced flow field effects and consequently to deviations in the position of the reaction zone. Instead, the radiation heat losses (described via the Stefan-Boltzmann law) were adjusted to match the calculated with the measured peak temperatures. The current approach works, because the heat losses due to the sampling probe are not local effects but of dimensions comparable to the 
reaction zone in which all intermediates are formed. A sensitivity analysis of the species maximum concentration to the heat loss value imposed in the model is provided in the Supplementary Material (Figs. S8-S10). Nothing in what is said here suggests that this approach models the physics of probe losses. The method just develops a temperature profile, which is closest to the experimental measurements and is still consistent with the flow calculation. The software is also capable to reread any suggested temperature profile, and returns identical species profiles.

\section{Results and discussion}

In this study, a total of 47 species (measured with both, the EI-MBMS and the PI-MBMS technique) were quantified from Flames $A$ and $B$ and compared to the predicted concentration profiles. Data of all quantified species are available in the Supplemental Material. Only a few profiles, which describe major observations, are discussed here. The main focus of the discussion will be on a detailed description of the formation of one- and two-ring aromatic species.

Experimental and modeled mole fraction profiles as function of the distance from the fuel outlet of the main species (Flame A) are depicted in Fig. 1. 


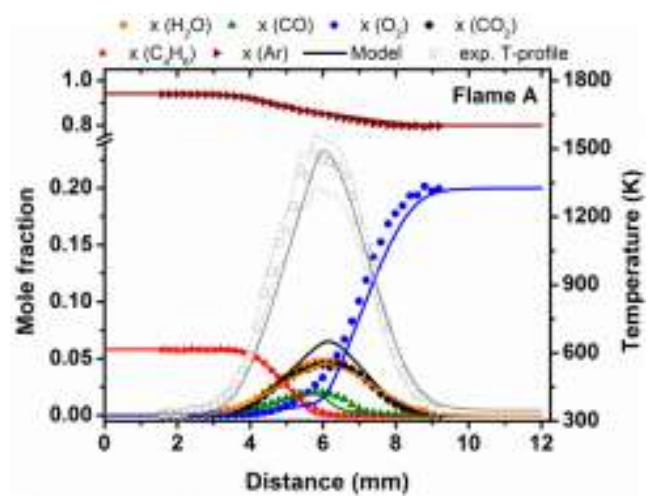

Figure 1: Experimental (symbols) and simulated (thick lines) mole fraction profiles of the main species $\left(1,3-\mathrm{C}_{4} \mathrm{H}_{6}\right.$, $\left.\mathrm{O}_{2}, \mathrm{Ar}, \mathrm{H}_{2} \mathrm{O}, \mathrm{CO}, \mathrm{CO}_{2}\right)$. The experimentally determined temperature profile is depicted as grey open symbols together with the modeled profile (solid grey line), upper and lower temperature limits are added as well (thin dashed grey lines).

Excellent agreement between modeling and experiment can be observed for most of the species. Observable deviations for $\mathrm{O}_{2}$ and $\mathrm{CO}_{2}$ are within the uncertainty limits of the experiment. Assuming that the model is capable to predict the major species' profiles, this level of agreement demonstrates the reliability of our experimental data and of the data evaluation procedure. Consequently, reliable intermediate species concentration profiles can be calculated because they are based on the reliable argon mole fraction profile.

The facts that the model captures 1,3-butadiene's laminar flame speeds (Fig. S11) and, as shown here, also the major species profiles and the positions of the reaction zones in the opposed-flow diffusion flames (Fig. 1 and Figs. S2-S3), give us confidence, that the developed mechanism provides an accurate description of the global 1,3-butadiene combustion chemistry. The modeling results show that the major species' mole fraction profiles are only slightly affected by the uncertainty of the temperature profiles in the proposed limits (Figs. S2-S3). The carbon monoxide profile, which usually agrees under these conditions well with experiments, 
suggests that the temperature measurements are not far from reality. Higher temperatures would increase the calculated CO concentrations (see also Fig. S10).

The model is also capable of accurately predicting the profiles of the speciation data from a low-pressure premixed flame [8] (Figs. S12-S14) and the major $C_{1}-C_{4}$ intermediates of the flames studied here as shown in Fig. 2 for Flame A and Flame B.

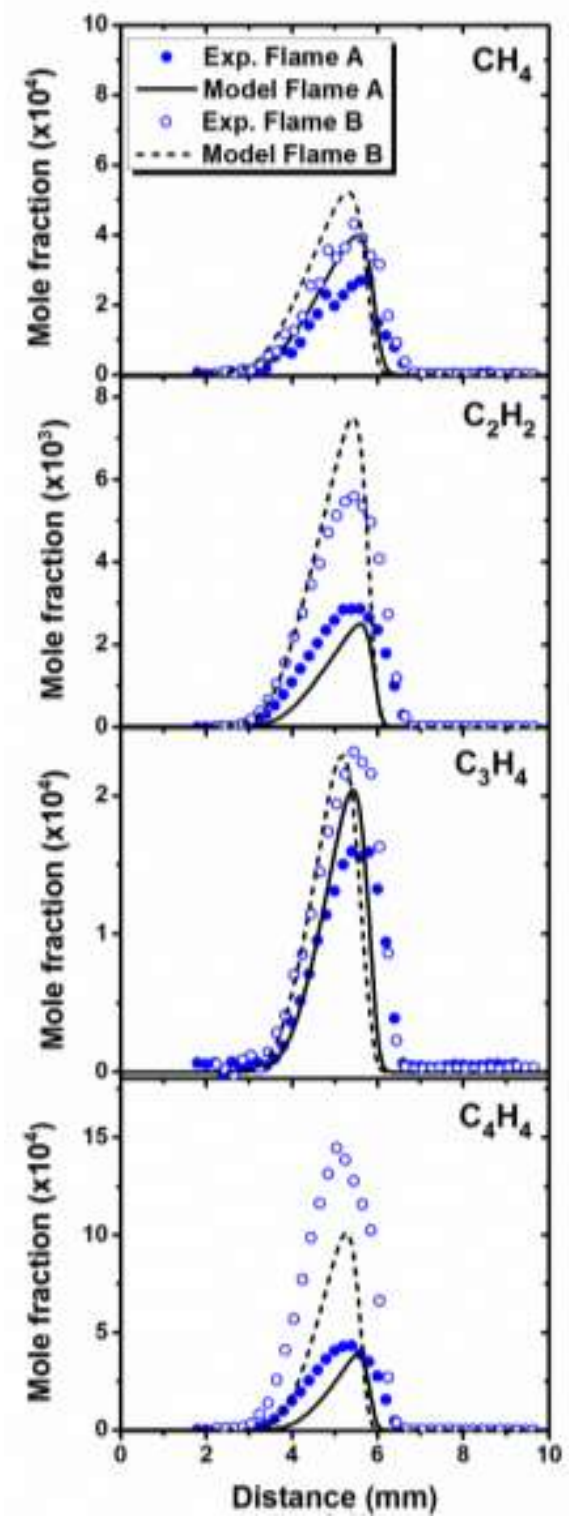

Figure 2: Experimental and simulated mole fraction profiles of selected $C_{1}-C_{4}$ species in Flame $A$ (closed symbols and solid lines) and Flame B (open symbols and dashed lines). 
Depending on the molecular fuel structure, the first step in fuel consumption is initiated by different reaction types. In particular, the $\mathrm{H}$-atom abstraction from the fuel molecule is the major consumption reaction, but isomerization [24], and dissociation reactions [25] have also been reported to be important. When a $\mathrm{C}=\mathrm{C}$ double-bond is present in the fuel molecule, radical-addition reactions should also be considered. In this work, the PI experiment allowed for detecting the $\mathrm{C}_{4} \mathrm{H}_{5}$ and $\mathrm{C}_{4} \mathrm{H}_{7}$ radicals by tuning the photon energy below the ionization threshold of $1,3-\mathrm{C}_{4} \mathrm{H}_{6}$ and thus avoiding contributions of fragments and ${ }^{13} \mathrm{C}$ isotopomers on the respective $\mathrm{m} / \mathrm{z}$ ratios. The peak value of $\mathrm{C}_{4} \mathrm{H}_{7}$ in Flame $\mathrm{A}$ is about a factor of 12 stronger than that of $\mathrm{C}_{4} \mathrm{H}_{5}$ indicating a higher concentration of $\mathrm{C}_{4} \mathrm{H}_{7}$ than $\mathrm{C}_{4} \mathrm{H}_{5}$ radicals and emphasizing the importance of initiating addition reactions in the 1,3-butadiene chemistry.

In this context, a remarkably strong signal was observed for $\mathrm{C}_{5} \mathrm{H}_{8}$. Although the formation of several isomers is conceivable, only 1,3-pentadiene was identified in the PI experiment. The abundance of 1,3-pentadiene might be explained by $\mathrm{CH}_{3}$ radical addition to the fuel molecule forming $\mathrm{C}_{5} \mathrm{H}_{9}$ and subsequently 1,3-pentadiene. However, it can also be formed by $\mathrm{CH}_{3}$ radical additions to the $n-\mathrm{C}_{4} \mathrm{H}_{5}$ radical $\left(\bullet \mathrm{CH}=\mathrm{CH}-\mathrm{CH}=\mathrm{CH}_{2}\right)$.

The experimental and modeled mole fraction profiles of $\mathrm{C}_{5} \mathrm{H}_{8}$ are shown in Fig. 3 . The predicted mole fractions are somewhat smaller than in the experiment, but the agreement is within the experimental uncertainty limits. It was essential to revise the mechanism to predict reasonable concentrations of $\mathrm{C}_{5} \mathrm{H}_{8}$. Specifically, the following formation/decomposition reactions for 1,3-pentadiene ( $\mathrm{C} 5 \mathrm{H} 8-13)$ were added to the model (Note, in the following discussion the model's nomenclature is used whenever discussing the flame chemistry as described in the model): $\mathrm{C} 5 \mathrm{H} 8-13 \rightleftarrows \mathrm{N}-\mathrm{C} 4 \mathrm{H} 5+\mathrm{CH} 3$ [26], $\mathrm{H}+\mathrm{C} 5 \mathrm{H} 8-13 \rightleftarrows \mathrm{C} 3 \mathrm{H} 5+\mathrm{C} 2 \mathrm{H} 4$ [27], and 
$\mathrm{C} 2 \mathrm{H} 3+\mathrm{C} 3 \mathrm{H} 6 \rightleftarrows \mathrm{C} 5 \mathrm{H} 8-13+\mathrm{H}[28]$. We also considered the formation of cyclopentadiene from 1,3butadiene following the suggestion from Ranzi et al. [29]. Lower concentrations were predicted in Flame $B$, probably caused by the temperature dependency of the $n-\mathrm{C}_{4} \mathrm{H}_{5}+\mathrm{CH}_{3}$ reaction.

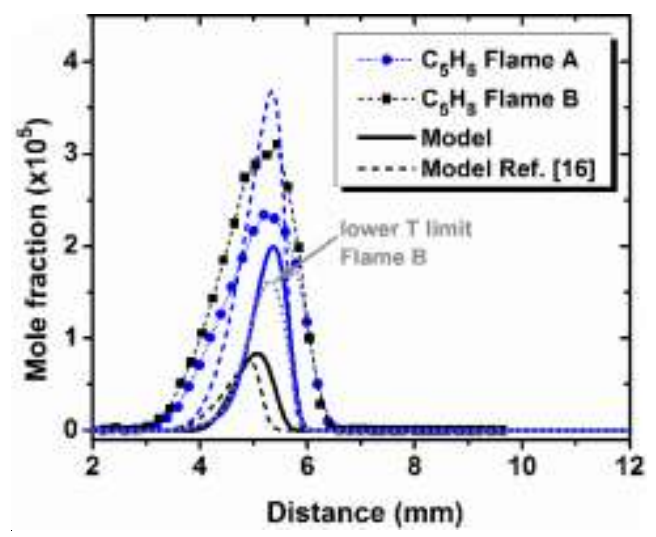

Figure 3: Experimental and simulated mole fraction profiles of $\mathrm{C}_{5} \mathrm{H}_{8}$ quantified in Flame $A$ and $B$.

The reaction flow analysis (Fig. 4) reveals that a direct methyl addition to one of the double bonds of the fuel is only a very minor (below 1\%) fuel consumption step. But, according to the updated model, 1,3-pentadiene $\left(\mathrm{C}_{5} \mathrm{H}_{8}\right)$ is almost exclusively formed by the reaction of $n$ $\mathrm{C}_{4} \mathrm{H}_{5}$ with $\mathrm{CH}_{3}$. The predicted $\mathrm{C}_{5} \mathrm{H}_{8}$ concentration (Fig. 3) shows a very strong sensitivity on the estimated heat losses. Using the lower temperature limit for Flame B results in a peak concentration of $1.6 \mathrm{E}-5$ for $\mathrm{C}_{5} \mathrm{H}_{8}$ which is a factor of 2 higher than the peak mole fraction obtained with the reference temperature profile. This value would be within the experimental uncertainty range. Note, that the reaction rates for the thermal decomposition of 1,3pentadiene and the formation via $\mathrm{CH} 3+\mathrm{N}-\mathrm{C} 4 \mathrm{H} 5$, have not yet been well studied and we based our rates on an analogy for the thermal decomposition of larger $n$-alkanes [26]. This uncertainty also contributes to the under/over prediction of $\mathrm{C}_{5} \mathrm{H}_{8}$ in both flames.

As predicted by the model, for Flame A, about half of the decomposition products of 1,3-pentadiene are $\mathrm{C}_{2-}$ and $\mathrm{C}_{3}$-species, but 1,3-cyclopentadiene (model: $\mathrm{CYC5H6)}$ and the 1,3- 
pentadiene-5-yl radical $\left(\mathrm{CH}_{2}=\mathrm{CH}-\mathrm{CH}=\mathrm{CH}-\mathrm{CH}_{2}, \mathrm{C} 5 \mathrm{H} 7-\mathrm{D} 1 \mathrm{D} 3 \mathrm{R} 5\right)$ are the major consumption products from 1,3-pentadiene. For Flame B, this consumption-path becomes more dominant and contributes to more than $80 \%$ of the 1,3-pentadiene consumption. The latter also can form 1,3-cyclopentadiene $\left(\mathrm{C}_{5} \mathrm{H}_{6}\right)$, which then, via the cyclopentadienyl radical $\left(\mathrm{C}_{5} \mathrm{H}_{5}, \mathrm{CYC5} \mathrm{H}^{-}\right.$) (see Fig. S15), serves as a precursor for naphthalene $\left(\mathrm{C}_{10} \mathrm{H}_{8}, \mathrm{~A} 2\right)[27]$.

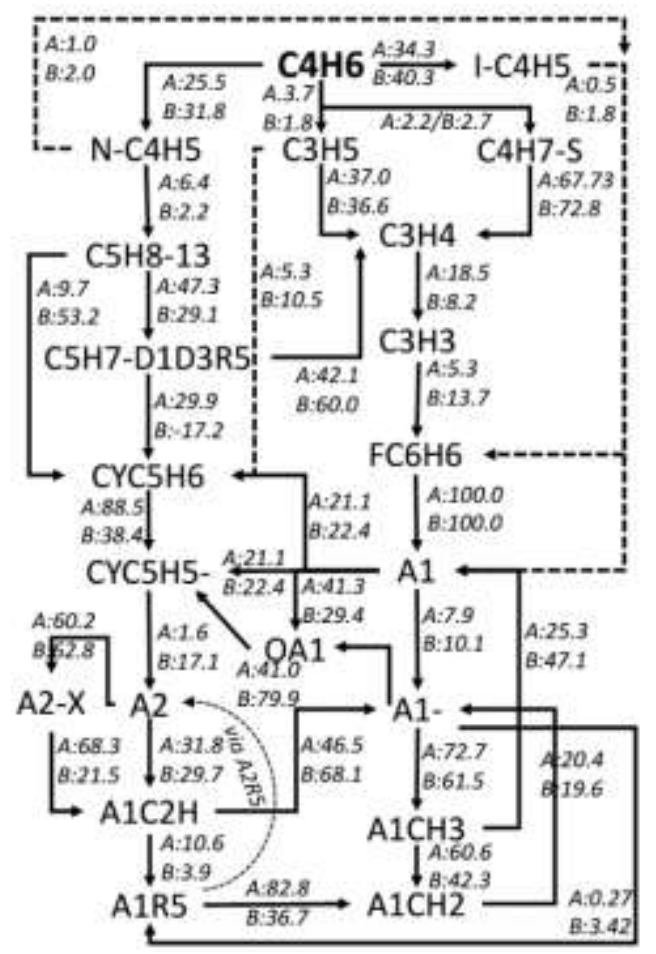

Figure 4: Major flow patterns contributing to the PAH formation in Flame A and Flame B based on integrated flows between the two nozzles. Italic numbers denote contribution of the respective pathway to the reactant consumption. More detailed flow analyses can be found in the Supplemental Material.

Because of the experimental uncertainties with respect to the radical species, we use the $\mathrm{C}_{5} \mathrm{H}_{6}$ concentration profile as an indicator for the model's performance. The experimental 
and modeled mole fraction profiles of 1,3-cyclopentadiene and naphthalene are shown in Fig. 5. Due to the small fuel mole fraction of Flame $A$, the signal-to-noise ratio of species with $m / z>94$ is low and Flame $A$ is therefore not suitable to give reliable experimental data of larger aromatic species. Species with higher $\mathrm{m} / \mathrm{z}$ are therefore just considered from Flame B. Note that the El experiment (used for the analysis of Flame B) does not allow for isomer separation and that for a given mass-to-charge ratio only one isomer was considered in the data evaluation process: in particular phenylacetylene on $m / z=102.047 \mathrm{u}\left(\mathrm{C}_{8} \mathrm{H}_{6}\right)$, indene on $\mathrm{m} / \mathrm{z}=116.063 \mathrm{u}$ $\left(\mathrm{C}_{9} \mathrm{H}_{8}\right)$, and naphthalene on $\mathrm{m} / \mathrm{z}=128.063 \mathrm{u}\left(\mathrm{C}_{10} \mathrm{H}_{8}\right)$. In the updated mechanism, possible pathways to form naphthalene were re-evaluated and several pathways were added to the mechanism: $\quad \mathrm{A} 1-+\mathrm{C} 4 \mathrm{H} 6 \rightleftarrows \mathrm{A} 2+3 \mathrm{H} \quad[30,31], \quad \mathrm{CYC} 5 \mathrm{H} 5-+\mathrm{CYC} 5 \mathrm{H} 6 \rightleftarrows \mathrm{A} 2+\mathrm{H} 2+\mathrm{H} \quad[29], \quad \mathrm{CYC} 5 \mathrm{H} 5-$ $+\mathrm{CYC} 5 \mathrm{H} 6 \rightleftarrows \mathrm{A} 1+\mathrm{N}-\mathrm{C} 4 \mathrm{H} 5$ [29], and $\mathrm{CYC} 5 \mathrm{H} 5-+\mathrm{A} 1 \rightleftarrows \mathrm{A} 2+\mathrm{CH} 3[29]$.

The comparison of predicted $\mathrm{C}_{5} \mathrm{H}_{6}$ and $\mathrm{C}_{10} \mathrm{H}_{8}$ mole fractions obtained with the mechanism reported in Ref. [16] (dashed lines) and the revised mechanism presented here (thick lines), emphasizes the importance of a known $\mathrm{C}_{5}$-chemistry to a proper prediction of PAH formation. The improved agreement was achieved by including the following reactions: $\mathrm{C} 3 \mathrm{H} 3+\mathrm{C} 2 \mathrm{H} 4 \rightleftarrows \mathrm{CYC} 5 \mathrm{H} 6+\mathrm{H}[32], \mathrm{CYC} 5 \mathrm{H} 6 \rightleftarrows \mathrm{C} 2 \mathrm{H} 2+\mathrm{C} 3 \mathrm{H} 4[33], \mathrm{C} 5 \mathrm{H} 8-13 \rightleftarrows \mathrm{CYC} 5 \mathrm{H} 6+\mathrm{H}+\mathrm{H}$ [29], and $\mathrm{C} 2 \mathrm{H} 3+\mathrm{C} 5 \mathrm{H} 8-13 \rightleftarrows \mathrm{CYC} 5 \mathrm{H} 6+\mathrm{C} 2 \mathrm{H} 5$ [29]. 


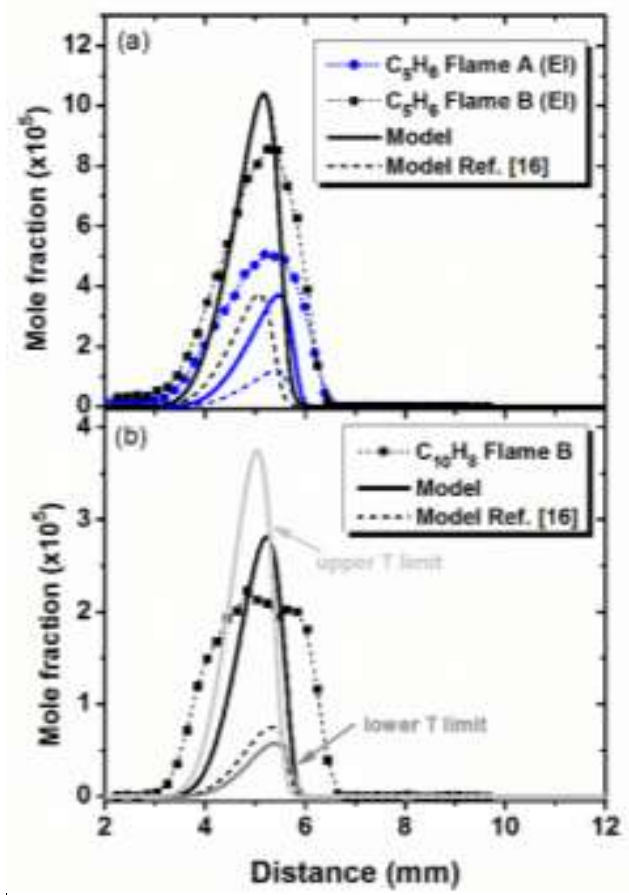

Figure 5: Experimental and modeled mole fraction profiles of (a) $\mathrm{C}_{5} \mathrm{H}_{6}$ and (b) $\mathrm{C}_{10} \mathrm{H}_{8}$. Thick dashed lines label simulations with the model provided in Ref. [16].

Interestingly, a strong temperature influence on the formation of naphthalene was observed. Fig. 5(b) displays the effect of the temperature uncertainty on the model predictions, which differ by a factor of 5.6 when referencing to upper and lower limit temperature profiles. The reasons for this behavior will be discussed later along with other aromatic species.

Besides the dehydrogenation pathways towards $\mathrm{C}_{5} \mathrm{H}_{5}$, the reaction flux analysis (Fig. 4) revealed two further pathways to $\mathrm{C}_{5} \mathrm{H}_{5}$, which both occur via benzene (A1). The first is the known oxidation reaction of benzene to $\mathrm{C}_{5} \mathrm{H}_{5}$ via an O-atom initiated HCO-loss, the second proceeds via the phenoxy radical (OA1). Thus, the prerequisite to reasonably predict naphthalene formation is a fundamental understanding of benzene formation.

A recent study [8] of a low-pressure premixed flame of 1,3-butadiene has shown that the addition reaction of $i-\mathrm{C}_{4} \mathrm{H}_{5}\left(\mathrm{CH}_{2}=\mathrm{CH}-\bullet \mathrm{C}=\mathrm{CH}_{2}\right)$ to $\mathrm{C}_{2} \mathrm{H}_{2}$ is of major importance and that 
reactions of propargyl $\left(\mathrm{C}_{3} \mathrm{H}_{3}\right)$ and allyl $\left(\mathrm{C}_{3} \mathrm{H}_{5}\right)$ radicals contribute as well. It is important to note that fulvene $\left(\mathrm{cyC}_{5} \mathrm{H}_{4} \mathrm{CH}_{2}, \mathrm{FC} 6 \mathrm{H} 6\right)$ is a main product of the first reaction and thus represents a key intermediate in the overall benzene formation chemistry [1] (see Fig. S16). Here, the PI experiment enabled the isomer-resolved quantification of fulvene and benzene in Flame $A$. Figure 6(a) shows the experimental and simulated mole fraction profiles of $\mathrm{C}_{6} \mathrm{H}_{6}$. Experimental data and modeling results agree well for the sum of all isomeric $\mathrm{C}_{6} \mathrm{H}_{6}$ intermediates (Flame B) and the two separated isomers benzene and fulvene (Flame A). To accurately predict the experimental data, the previous model was updated according to the suggestions of Senosiain et al. [1].

As shown in the flux analysis (Fig. 4), the $\mathrm{C}_{4} \mathrm{H}_{5}+\mathrm{C}_{2} \mathrm{H}_{2}$ pathways may not be important for the consumption of the $\mathrm{C}_{4} \mathrm{H}_{5}$ radicals, but they contribute up to $15 \%$ to the benzene and $50 \%$ of the fulvene formation. Due to the abundance of $\mathrm{C}_{4} \mathrm{H}_{5}$ radicals formed by the fuel, these pathways are a major entry point to the PAH formation. Detailed breakdown schemes are shown in Figs. S17-S20 for Flame A and in Figs. S21-S22 for Flame B.

Considering the importance of benzene in the formation of the second aromatic ring (see Fig. 4), the shown good agreement between model and experiment can be seen as a good basis for the assessment of the model's capabilities to predict further aromatic ring formation. 


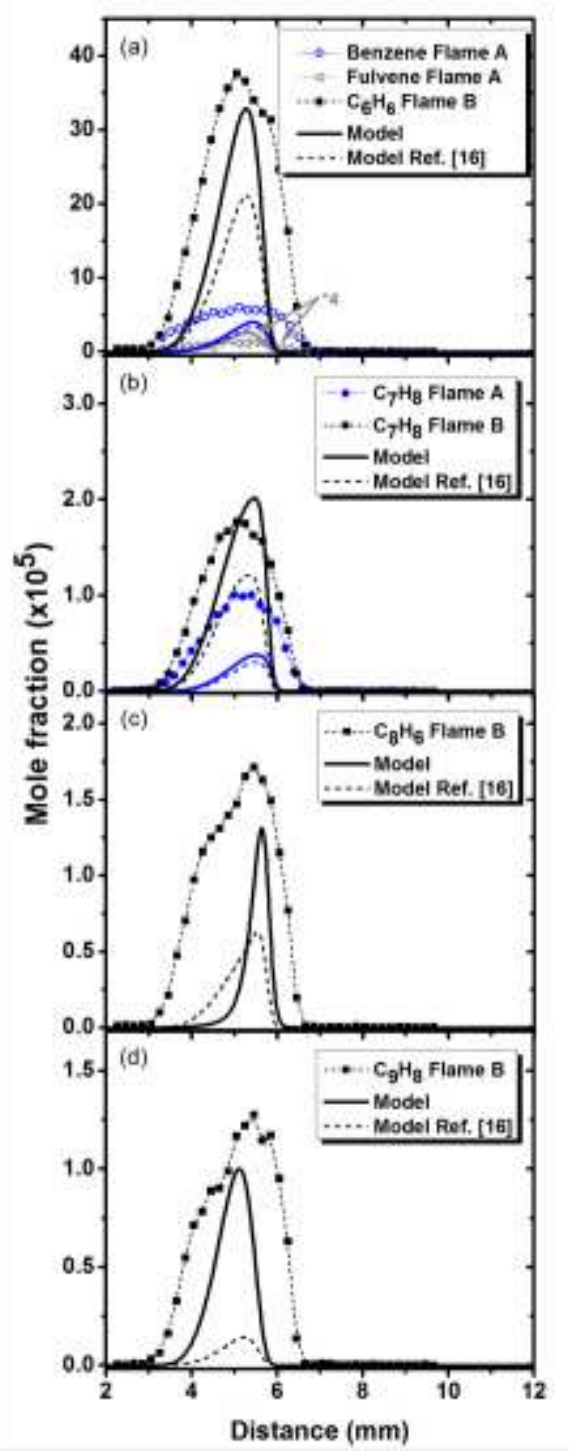

Figure 6: Experimental and modeled mole fraction profiles of (a) benzene and fulvene quantified by PI (Flame A) as well as $\mathrm{C}_{6} \mathrm{H}_{6}$ (Flame B), (b) $\mathrm{C}_{7} \mathrm{H}_{8}$, (c) $\mathrm{C}_{8} \mathrm{H}_{6}$, and (d) $\mathrm{C}_{9} \mathrm{H}_{8}$ quantified by El. Thick dashed lines label simulations with the model provided in Ref. [16].

As shown in the flux analysis in Fig. 4 the model predicts that the chemistry of aromatic species is strongly connected. Typical species, which are considered in this context, are $\mathrm{C}_{7} \mathrm{H}_{8}$, $\mathrm{C}_{8} \mathrm{H}_{6}$, and $\mathrm{C}_{9} \mathrm{H}_{8}$, with their experimental and modeling profiles shown in Figs. $6(\mathrm{~b})-(\mathrm{d})$. Note that these species are here assumed to be only toluene, phenylacetylene, and indene, respectively. 
No changes in the mechanism were made with regard to the $\mathrm{C}_{7} \mathrm{H}_{8}$ chemistry. The improved prediction in Flame B [Fig. 6(b)] is a result of a more accurate description of the benzene formation.

For $\mathrm{C}_{8} \mathrm{H}_{6}$, the flow analysis reveals that at temperatures such as that prevailed in Flame A (and in Flame B at the lower temperature limit) phenylacetylene is preferably formed via the cyclopentadiene $(\mathrm{CYC5H6}) \rightarrow$ cyclopentadienyl $(\mathrm{CYC} 5 \mathrm{H} 5-) \rightarrow$ naphthalene $(\mathrm{A} 2) \rightarrow$ phenylacetylene $(\mathrm{A} 1 \mathrm{C} 2 \mathrm{H})$. The flux analysis reveals that about $1 / 3$ of the cyclopentadiene is formed from $1,3-$ pentadiene ( $\mathrm{C} 5 \mathrm{H} 8-13)$ and the 1,3-pentadien-5-yl radical (C5H7-D1D3R5). For Flame $\mathrm{B}$ the formation of cyclopentadienyl from $\mathrm{C}_{6} \mathrm{H}_{6}$ isomers becomes more dominant and and about 4/5 of cyclopentadienyl are formed via these species. The mechanism predicts $\mathrm{A} 1 \mathrm{C} 2 \mathrm{H}$ formation originating from $\mathrm{A} 2$ (via $\mathrm{A} 2+\mathrm{OH} \rightarrow \mathrm{HCO}+\mathrm{CH}_{2}-3+\mathrm{A} 1 \mathrm{C} 2 \mathrm{H}$ ), explaining the appearance of the modeled $\mathrm{C}_{10} \mathrm{H}_{8}$ peak at lower distances from the fuel outlet $(5.25 \mathrm{~mm})$ than that of $\mathrm{C}_{8} \mathrm{H}_{6}$ $(5.6 \mathrm{~mm})$. This peak position is in good agreement with the observed maximum of the experimental mole fraction profile (Fig. 6(c)) arguing that a major part of phenylacetylene in Flame $B$ is formed by naphthalene consumption. Although the model is capable of predicting the observed peak concentrations of $\mathrm{C}_{8} \mathrm{H}_{6}$ [Fig. 6(c)], the experimental profile exhibits a somewhat different shape than the modeled one. It features a shoulder at lower distances which is not captured by the model. However, the apparent shoulder indicates, that in this flame also other molecular-growth reactions contribute to the phenylacetylene formation. More work is necessary in this regard.

The last point we discuss here is the indene formation. To achieve the indicated improvement compared to the results from the base model [16] and the overall level of 
agreement between modeled and experimental mole fraction profile of $\mathrm{C}_{9} \mathrm{H}_{8}$ [Fig. 6(d)], several changes were made to the mechanism: We included the cyclization reactions of the benzyl radical with 1,3-butadiene and the 1,3-butadiene-1-yl radical $\left(n-\mathrm{C}_{4} \mathrm{H}_{5}\right)$ as proposed by Fascella et al. [34] and the addition reaction of methyl to phenylacetylene ( $\mathrm{A} 1 \mathrm{C} 2 \mathrm{H})$ using a rate for a similar reaction from Marinov et al. [27]. Furthermore, an indene formation pathway via cycloheptatriene suggested by Savee et al. [35] was added but found not to contribute.

Assuming that indene is only formed through methyl addition to phenylacetylene, its concentration should peak at larger distances from the fuel outlet than that of $\mathrm{C}_{8} \mathrm{H}_{6}$. However, the simulated profile of indene exhibits an earlier maximum at $5.1 \mathrm{~mm}$ compared to $5.6 \mathrm{~mm}$ of $\mathrm{C}_{8} \mathrm{H}_{6}$. The flow analysis shows that with rising peak temperatures, and thus for Flame $\mathrm{B}$, indene formation via the addition of propargyl $\left(\mathrm{C}_{3} \mathrm{H}_{3}\right)$ to the phenyl radical becomes more important and leads to a broader profile, which, as a consequence, is shifted closer to the fuel outlet. The experimental profile of indene also shows a shoulder at smaller distances indicating contributions from growth reactions that are not yet considered. The experimental spatial resolution is not sufficient to resolve the growth of phenyacetylene to indene, i.e., $\mathrm{C}_{8} \mathrm{H}_{6}$ and $\mathrm{C}_{9} \mathrm{H}_{8}$ peak at the same position.

The model predicts that at high temperatures (in particular at the high temperature limit of Flame B) indene is consumed over a two-step-reaction. An H-abstraction followed by the addition of propargyl forms first acenaphthalene (A2R5) (Fig. 4), which then reacts rapidly to naphthalene ( $\mathrm{A} 2 \mathrm{R} 5+\mathrm{OH} \rightleftarrows \mathrm{A} 2+\mathrm{HCCO})$. This route contributes only with $3 \%$ to naphthalene formation in Flame $\mathrm{A}$, but is rising up to $40 \%$ for the high temperature limit of Flame $\mathrm{B}$. This 
observation explains the strong temperature dependency of naphthalene formation that was mentioned above and reveals again the strong interconnectivity of aromatics' chemistry.

\section{Conclusions}

From a combined experimental and modeling study of opposed-flow 1,3-butadiene flames at near atmospheric pressure, we conclude that $\mathrm{C}_{4} \mathrm{H}_{5}$ radicals play an important role in aromatic ring formation. First, the $i-\mathrm{C}_{4} \mathrm{H}_{5}+\mathrm{C}_{2} \mathrm{H}_{2}$ reaction contributes significantly via fulvene to benzene formation. The model also predicts this reaction to be important in a 1,3-butadiene lowpressure premixed flame confirming earlier results [8]. Second, the isomeric $n-\mathrm{C}_{4} \mathrm{H}_{5}$ radical contributes to the formation of naphthalene via a multi-step reaction route which involves the recombination of the fuel radical with $\mathrm{CH}_{3}$ forming 1,3-pentadiene and subsequent oxidation to the $\mathrm{C}_{10} \mathrm{H}_{8}$ precursor cyclopentadienyl. This observation shows the importance of the $\mathrm{C}_{5^{-}}$ chemistry in aromatic ring formation and emphasizes the need to investigate $\mathrm{C}_{5}$-flames close to the sooting limit.

These conclusions are based on mole fraction profiles from flame-sampling molecularbeam mass spectrometry and on a hierarchically constructed mechanism which is continuously updated and validated against speciation data from premixed low-pressure flames, laminar flame speeds at different pressures, and ignition delay time measurements. It should be kept in mind that a different chemically detailed model may predict different reaction paths to be important.

A performed reaction path analysis has shown that the chemistry of aromatic species is strongly connected. Specifically, naphthalene was predicted to contribute to the formation of 
phenylacetylene and thus influences the indene formation. It was revealed that consumption reactions of larger aromatics can be of similar importance than molecular growth reactions to the formation of smaller aromatics.

\section{Acknowledgements:}

This material is based upon work supported by the U.S. Department of Energy (DOE), Office of Science, Office of Basic Energy Sciences. We thank Paul Fugazzi for technical assistance. YW, HS, and SMS acknowledge funding from King Abdullah University of Science and Technology. The Advanced Light Source is supported by the Director, Office of Science, Office of Basic Energy Sciences, of the U.S. DOE under Contract No. DEAC02-05CH11231. Sandia is a multi-program laboratory operated by Sandia Corporation, a Lockheed Martin Company, for the National Nuclear Security Administration under contract DE-AC04-94-AL85000.

\section{References}

[1] J.P. Senosiain, J.A. Miller, J. Phys. Chem. A 111 (2007) 3740-3747.

[2] H.A. Gueniche, P.A. Glaude, R. Fournet, F. Battin-Leclerc, Combust. Explos. Shock WAVES 42 (2006) 702-707.

[3] H.A. Gueniche, P.A. Glaude, R. Fournet, F. Battin-Leclerc, Combust. Flame 151 (2007) 245-261.

[4] N. Olten, S. Senkan, Combust. Flame 125 (2001) 1032-1039.

[5] S. Granata, T. Faravelli, E. Ranzi, N. Olten, S. Senkan, Combust. Flame 131 (2002) 273- 
284.

[6] J.A. Cole, J.D. Bittner, J.P. Longwell, J.B. Howard, Combust. Flame 56 (1984) 51-70.

[7] R.P. Lindstedt, G. Skevis, Proc. Combust. Inst. 26 (1996) 703-709.

[8] N. Hansen, J.A. Miller, T. Kasper, K. Kohse-Höinghaus, P.R. Westmoreland, J. Wang, T.A. Cool, Proc. Combust. Inst. 32 (2009) 623-630.

[9] S.A. Skeen, H.A. Michelsen, K.R. Wilson, D.M. Popolan, A. Violi, N. Hansen, J. Aerosol Sci. 58 (2013) 86-102.

[10] K.O. Johansson, J.Y.W. Lai, S.A. Skeen, D.M. Popolan-Vaida, K.R. Wilson, N. Hansen, A. Violi, H.A. Michelsen, Proc. Combust. Inst. 35 (2014) 1819-1826.

[11] A. Lucassen, S. Park, N. Hansen, S.M. Sarathy, Proc. Combust. Inst. 35 (2014) 813-820.

[12] S.R. Leone, M. Ahmed, K.R. Wilson, Phys. Chem. Chem. Phys. 12 (2010) 6564-6578.

[13] K. Moshammer, S. Vranckx, H.K. Chakravarty, P. Parab, R.X. Fernandes, K. KohseHöinghaus, Combust. Flame 160 (2013) 2729-2743.

[14] M. Schenk, L. Leon, K. Moshammer, P. Oßwald, T. Zeuch, L. Seidel, F. Mauss, K. KohseHöinghaus, Combust. Flame 160 (2013) 487-503.

[15] F.N. Egolfopoulos, N. Hansen, Y. Ju, K. Kohse-Höinghaus, C.K. Law, F. Qi, Prog. Energy Combust. Sci. 43 (2014) 36-67.

[16] L. Seidel, K. Moshammer, X. Wang, T. Zeuch, K. Kohse-Höinghaus, F. Mauss, Combust. Flame 162 (2015) 2045-2058. 
[17] K. Hoyermann, F. Mauss, T. Zeuch, Phys. Chem. Chem. Phys. 6 (2004) 3824-3835.

[18] P. Oßwald, K. Kohse-Höinghaus, U. Struckmeier, T. Zeuch, L. Seidel, L. Leon, F. Mauss, Zeitschrift Für Phys. Chemie 225 (2011) 1029-1054.

[19] A. Nawdiyal, N. Hansen, T. Zeuch, L. Seidel, F. Mauss, Proc. Combust. Inst. 35 (2015) 325-332.

[20] J. Senosiain, S.J. Klippenstein, J. Miller, J. Phys. Chem. A 109 (2005) 6045-6055.

[21] D. Baulch, C. Bowman, C. Cobos, J. Phys. Chem. Ref. Data 34 (2005) 757.

[22] E. Goos, A. Burcat, B. Ruscic, Ext. Third Millenium Ideal Gas Thermochem. Database with Updat. from Act. Thermochem. Tables (2015) http://burcat.technion.ac.il/dir ; 2015-11.

[23] Http://www.loge.se/Products/LOGEsoft.html, (n.d.).

[24] S.A. Skeen, B. Yang, A.W. Jasper, W.J. Pitz, N. Hansen, Energy and Fuels 25 (2011) 56115625.

[25] N. Hansen, W. Li, M.E. Law, T. Kasper, P.R. Westmoreland, B. Yang, T.A. Cool, A. Lucassen, Phys. Chem. Chem. Phys. 12 (2010) 12112-12122.

[26] S.S. Ahmed, F. Mauss, G. Moréac, T. Zeuch, Phys. Chem. Chem. Phys. 9 (2007) 11071126.

[27] N. Marinov, W. Pitz, C. Westbrook, Combust. Flame 114 (1998) 192-213.

[28] W. Tsang, J. Phys. Chem. Ref. Data 20 (1991) 221-274.

[29] E. Ranzi, C. Cavallotti, A. Cuoci, A. Frassoldati, M. Pelucchi, T. Faravelli, Combust. Flame 
162 (2014) 1679-1691.

[30] R.I. Kaiser, D.S.N. Parker, A.M. Mebel, Annu. Rev. Phys. Chem. 66 (2014) 43-67.

[31] P. Lindstedt, L. Maurice, M. Meyer, Faraday Discuss. 119 (2001) 409-432.

[32] A. Laskin, H. Wang, C.K. Law, Int. J. Chem. Kinet. 32 (2000) 589-614.

[33] G.B. Bacskay, J.C. Mackie, Phys. Chem. Chem. Phys. 3 (2001) 2467-2473.

[34] S. Fascella, C. Cavallotti, R. Rota, S. Carra, J. Phys. Chem. A 108 (2004) 3829-3843.

[35] J.D. Savee, T.M. Selby, O. Welz, C.A. Taatjes, D.L. Osborn, J. Phys. Chem. Lett. (2015) 4153-4158. 


\section{Figure caption list}

Figure 7: Experimental (symbols) and simulated (thick lines) mole fraction profiles of the main species $\left(1,3-\mathrm{C}_{4} \mathrm{H}_{6}, \mathrm{O}_{2}, \mathrm{Ar}, \mathrm{H}_{2} \mathrm{O}, \mathrm{CO}, \mathrm{CO}_{2}\right)$. The experimentally determined temperature profile is depicted as grey open symbols together with the modeled profile (solid grey line), upper and lower temperature limits are added as well (thin dashed grey lines).

Figure 8: Experimental and simulated mole fraction profiles of selected $C_{1}-C_{4}$ species in Flame $A$ (closed symbols and solid lines) and Flame B (open symbols and dashed lines).

Figure 9: Experimental and simulated mole fraction profiles of $\mathrm{C}_{5} \mathrm{H}_{8}$ quantified in Flame $A$ and $B$.

Figure 10: Major flow patterns contributing to the PAH formation in Flame $\mathrm{A}$ and Flame $\mathrm{B}$ based on integrated flows between the two nozzles. Italic numbers denote contribution of the respective pathway to the reactant consumption. More detailed flow analyses can be found in the Supplemental Material.

Figure 11: Experimental and modeled mole fraction profiles of (a) $\mathrm{C}_{5} \mathrm{H}_{6}$ and (b) $\mathrm{C}_{10} \mathrm{H}_{8}$. Thick dashed lines label simulations with the model provided in Ref. [16].

Figure 12: Experimental and modeled mole fraction profiles of (a) benzene and fulvene quantified by $\mathrm{PI}$ (Flame A) as well as $\mathrm{C}_{6} \mathrm{H}_{6}$ (Flame B), (b) $\mathrm{C}_{7} \mathrm{H}_{8},(\mathrm{c}) \mathrm{C}_{8} \mathrm{H}_{6}$, and (d) $\mathrm{C}_{9} \mathrm{H}_{8}$ quantified by El. Thick dashed lines label simulations with the model provided in Ref. [16]. 